\title{
Being an American 2nd Year Medical Student in the COVID-19 Pandemic
}

Benjamin D. Liu. ${ }^{1}$

\section{The Experience}

Four months ago, nobody could have guessed just how disruptive COVID-19 would be. The first case was reported in Washington, United States on January 20th, 2020. ${ }^{1}$ While spreading rapidly, it mainly spared the mid-west United States where my medical school is located. Just over a month and a half ago, cases were still low in my state and I was fully expecting to finish my school year and take my Step 1 medical licensing exam with minimal disruptions. By the time March 12th, 2020 rolled around, several cases appeared in our state and thus my school decided to move all classes completely online while keeping exams on campus. A week later, all school services went remote, including exams and all non-essential employees after the community spread intensified. Most importantly, the one exam that essentially determines which residency programs or even which area of medicine you can apply to, is cancelled until April 3oth (likely much longer). Today, the United States remains the hardest-hit region in the world standing at 829,000 cases as of April 22nd, 2020. ${ }^{2}$

For most 2nd year US medical students, March-June is basically quarantine. While yes, a bit overstated, most students spend at least a month dedicated to 8+ hours per day of reviewing, doing practice questions, and flashcards in preparation for the Step 1 medical licensing exam. With a test date near the end of June, the lockdowns currently in effect have not changed my plans very much. However, for many 2 nd year medical students who normally study on campus, in coffee shops, or libraries, are struggling to focus studying at home all day. Even worse, a substantial number of students were supposed to take Step 1 in March or April. Reading their posts in online medical student forums, I cannot imagine spending all that time to prepare, just to have the exam they were supposed to take the next day canceled and delayed for another month and a half at least. Communication from the testing company has been poor, and anger and frustration from medical students is strong. Many students describe feeling unmotivated, anxious, and aimless even. I identify with these feelings and feel the cabin fever that many medical students are feeling as I approach day 42 of quarantine. Nevertheless, as I hear about what our fellow 3rd and 4th-year American students are going through - canceled in-clinic learning opportunities, uncertainty about graduation and rumors about being forced to work as an unpaid, tuition-paying 4th-year student at a resident level - I understand that the big takeaway is that medical students, as a community, are going through unprecedented difficulty and need to support each other. ${ }^{3}$

Beyond Step 1, not much has not changed. Reading an Italian Medical Student's experience during the outbreak, a major difference between my experience and theirs was the fact that most of our lectures were already streamed online. ${ }^{4}$ It's well known that many U.S. medical students do not go to class; over a third $(34.9 \%)$ of medical students never or "occasionally" attend virtual classes and almost half (48.1\%) do the same for in-person classes. ${ }^{5}$ As a result, besides the change of no longer having to go to mandatory classes, the daily 2nd-year medical student class experience has not changed. For our exams, our school (like a significant number of other medical schools at this moment) are currently being delivered remotely. When taking the exam, we need to have the webcam open and are not allowed to look anywhere but the screen. If we do, it will be flagged for review by exam proctors later. Nevertheless, other than the "big brother" feel to it, the exam situation has been quite reasonable as our exams were taken electronically before the pandemic as well.

Finally, any extracurriculars that 2nd-year students may be involved in are generally on hold. Because of the Step 1 dedicated period, most of our extracurriculars have already been handed off to the first-year students for leadership, therefore 2nd-year students were not generally affected. Nevertheless, seeing the ability of first-year students to adapt the organizations to this time has been amazing. For example, the free clinic associated with our school has now moved completely online to telehealth, while dispensing any medications in person with protective measures in place - all thanks to the leadership of the $1^{\text {st }}$ year student director board.

In conclusion, a significant portion of 2nd year US medical students' class and extracurricular experience have not been affected very much. Instead, many of our Step 1 licensing exam plans have been completely disrupted leading to anger and uncertainty over this extremely important exam. Organizations should remember that communication with their patrons is very important, especially in times of crisis. US medical students should continue support each other and remember that this too shall pass.

\footnotetext{
1 Medical Student, Medical College of Wisconsin, WI, USA.
}

About the Author: Benjamin D. Liu is currently a 2nd year medical student at the Medical College of Wisconsin in Milwaukee, USA of a 4-year MD program. He is currently in the middle of studying for the Step 1 medical licensing exam. 


\section{Experience}

\section{References}

1. Holshue ML, Debolt C, Lindquist S, Lofy KH, Wiesman J, Bruce H, et al. First Case of 2019 Novel Coronavirus in the United States. N Engl J Med. 2020 Mar 5;382(10):929-936.

2. COVID-19 Coronavirus pandemic. Worldometer. 2020. Last updated April 22, 2020; cited April 22, 2020.2 Available from: https://www.worldometers.info/coronavirus/.

3. Vishal Kheptal. Many Medical Students Are Willing to Go to the Front Lines. But We Need Pay and Protection. Last updated: April 2, 2020; cited April 21, 2020.
Available from: https://slate.com/technology/2020/04/coronavirus-medicalstudents-protection-tuition-insurance.html.

4. Biavardi NG. Being an Italian Medical Student During the COVID-19 Outbreak. Int Med Students. 2020 Jan-Apr;8(1):49-50.

5. Association of American Medical Colleges, AAMC. Medical School Year Two Questionnaire. Last updated: 2020 March; cited: April 22, 2020. Available from: https://www.aamc.org/system/files/2020-

04/2019\%20Y2Q\%20All\%20Schools\%20Summary\%20Report.pdf.

\section{Acknowledgments}

None.

Conflict of Interest Statement at Funding

The Authors have no funding, financial relationships or conflicts of interest to disclose.

Author Contributions

Conceptualization, Writing - Original Draft Preparation, and Writing - Review đ Editing: BDL.

Cite as:

Liu BD. Being an American 2nd Year Medical Student in the COVID-19 Pandemic. Int J Med Students. 2020 Jan-Apr;8(1):77-78.

This work is licensed under a Creative Commons Attribution 4.0 International License

ISSN 2076-6327

This journal is published by the University Library System, University of Pittsburgh as part of the Digital Publishing Program and is co-sponsored by the University of Pittsburgh Press. 